Dhaka Univ. J. Sci. 60(2): 283-288, 2012 (July)

\title{
Annealing Effects on the Properties of Chemically Deposited CdS Thin Films at Ambient Condition
}

\author{
G. Mustafa ${ }^{1}$, M. R. I. Chowdhury ${ }^{2}$, D. K. Saha ${ }^{3}$, S. Hussain ${ }^{2}$, and O. Islam ${ }^{2 \#}$ \\ ${ }^{1}$ Department of Physics, Jagannath University, Dhaka-1100, Bangladesh \\ ${ }^{2}$ Department of Physics, University of Dhaka, Dhaka 1000, Bangladesh \\ ${ }^{3}$ Materials Science Division, Atomic Energy Centre, Dhaka 1000, Bangladesh
}

Received on 25. 02. 2012. Accepted for Publication on 08. 05. 2012.

\begin{abstract}
Chemically-deposited CdS thin films have been investigated using various techniques to discuss annealing effects on the structural, morphological, optical and electrical properties of the films. It has been observed from XRD that the deposited layers are mainly consisting of CdS phase. After annealing, metastable cubic phase was transformed into stable hexagonal phase. The average grain sizes were found to increase and the lattice constant, micro-strain and dislocation density were found to decrease after annealing. Optical absorption measurements show that band gap is observed to be $2.42 \mathrm{eV}$ for as deposited and be $2.27 \mathrm{eV}$ upon heat treatment at $673 \mathrm{~K}$ for one hour in air. The conductivity of this film has been determined by I-V measurement and observed to increase with increase of temperature. The activation energy of electrical conductivity of this film is also determined.
\end{abstract}

Keywords: Chemically deposited CdS, XRD, SEM and optical properties.

\section{Introduction}

Over the years, chalcogenide semiconductors of II- VI group have attracted considerable attention because of their applications in optoelectronic devices. $\mathrm{CdS}$ is one of such compound in this group and its physical properties have been investigated extensively for both fundamental and practical purpose. In recent years, research has been performed in the area of preparation and characterization of CdS thin films. CdS thin films attracted much interest because of their preferred properties of wide energy gap, a good transparency in region of visible light, highabsorption coefficient, electron affinity, low resistivity, easy ohmic contact and excellent photoconductive property. The excellent optical properties of $\mathrm{CdS}$ make it suitable for use in solar cells, photoconductor and diode laser $[1,2]$. Being an n-type semiconductor material it has been observed that $\mathrm{CdS}$ is an excellent heterojunction solar cell partner of p-type narrow band gap semiconductor material like CdTe or $\mathrm{CuInSe} 2$, where $\mathrm{CdS}$ layer is used as the window material. Till today, researchers have tried to use different techniques to investigate the optical and structural properties, but the identification of the best electronic quality for photovoltaic applications is challenging due to the thin film nature of the solar cells. Polycrystalline $\mathrm{CdS}$ thin films have been prepared by diverse techniques including chemical bath deposition (CBD) [2, 3-15], electrodeposition [16], laser ablation [17], sputtering [18], vacuum evaporation [19] etc. Among these various techniques, CBD presents several advantages over other techniques for film processing namely i) it involves relatively simple and very economical equipment facilities; ii) films can be fabricated on large and irregular surfaces; iii) low temperature processing; iv) controllable film thickness. Moreover, CBD gives the best photoconductivity and morphological properties such as roughness and pinhole density when compared to films processed by other techniques [20]. Using a CBD, CdS as a buffer layer efficiency exceeding $17 \%$ has been achieved in $\mathrm{CuInSe}_{2}$-based thin film [4]. So due to its practical importance, it is necessary to perform characterization of thermal properties, which include surface homogeneity and intrinsic defects, etc.

In our previous paper, we have reported the characterization of CdS thin film deposited by CBD technique [21]. This article reports the effect of thermal annealing of chemically deposited $\mathrm{CdS}$ films onto the transparent conducting oxide (TCO) glass substrate.

\section{Experimental Details}

\section{Film deposition}

In this present study CdS thin film was prepared on TCO glass substrates using CBD technique. In order to obtain good adherence and uniformity for the films it is important to provide clean substrates to the CBD system. Since the contaminated surface provides nucleation sites facilitating the growth which results non-uniform film growth. The TCO substrates were cleaned with detergent, dried and degreased with acetone. After that it is boiled with distilled water and finally dried in air prior to film deposition.

The chemicals used for the preparation of thin film were analytical grade of purity more than $99.9 \%$. An aqueous chemical bath contains $0.02 \mathrm{M}$ cadmium chloride $\left(\mathrm{CdCl}_{2}\right)$, $0.07 \mathrm{M}$ ammonium chloride $\left(\mathrm{NH}_{4} \mathrm{Cl}\right)$ and $0.14 \mathrm{M}$ thiourea $\left(\mathrm{H}_{2} \mathrm{NCSNH}_{2}\right)$. The $\mathrm{pH}$ of the solution was 10.7 . The substrates were kept vertically in the bath containing reaction mixture. The solution was maintained under constant magnetic stirring during the deposition at a temperature of $263 \mathrm{~K}$ and deposition was allowed for 40 minutes. At the end of the deposition process, the films were taken out from the bath and immediately rinsed with hot distilled water and finally dried in

\#Corresponding Author (O. Islam): Fax: +880-2-8615583; E-mail: oislambd@yahoo.com 
blowing air. After complete drying, the films were annealed at $673 \mathrm{~K}$ for 1 hour in air ambient in order to enhance their structural property. The thickness of the film was found to be approximately $0.36 \mu \mathrm{m}$, determined by data pack in spectrophotometer.

\section{Characterization techniques}

The conductivity type measurements of CdS films were carried out by photoelectrochemical (PEC) cell arrangement where a $\mathrm{CdS} / \mathrm{NaCl}$ electrolyte (solid/ liquid) junction was illuminated by white light. Conventional Xray diffraction (XRD) technique was performed for studying bulk structure of the films using Philip PW-3040 X'Pert PRO X-ray diffractometer of $\mathrm{Cu} \mathrm{K}_{\alpha}$ radiation $\left(\lambda_{\alpha}=\right.$ 1.54056 ) and accelerated voltage was set at $40 \mathrm{kV}$ with $30 \mathrm{~mA}$. Surface morphology of the film was examined using scanning electron microscopy (SEM) (Model S3400N Hitachi, Japan) attached with an energy dispersive $\mathrm{X}$-ray (EDX) analyzer to measure the sample stoichiometry quantitatively. In order to study optical properties, optical absorption spectra were recorded in the wavelength range 400-1100 $\mathrm{nm}$ using a UV-1201V spectrophotometer, Shimadzu, Japan. The electrical conductivity of the film was measured using a two-probe method in the temperature range $273-373 \mathrm{~K}$. A laboratory dc power supply (Topward-3303D, China), and digital multimeter (Fluke 15B, China) were used for the measurement. Area of the film was defined $\left(1.44 \mathrm{~cm}^{2}\right)$ and aluminum coating with silver paste was applied to ensure good ohmic contacts to the film. In order to remove any contaminants from the surface, $\mathrm{CdS}$ layers were etched in a dilute $\mathrm{NaOH}+\mathrm{Na}_{2} \mathrm{~S}_{2} \mathrm{O}_{3}$ solution prior to aluminum coating.

\section{Results and Discussion}

\section{Reaction Mechanism}

$\mathrm{CdS}$ thin films were prepared by decomposition of thiourea $\left(\mathrm{NH}_{2}\right)_{2} \mathrm{CS}$ in an alkaline solution containing a cadmium salt. The reaction mechanism for deposition of CdS films has been reported previously [21]. In aqueous solution cadmium chloride dissociates to give $\mathrm{Cd}^{2+}$ ions. Hydrolysis of ammonia in water gives $\mathrm{OH}^{-}$ions, which forms complex cadmium tetraammine ion $\mathrm{Cd}\left(\mathrm{NH}_{3}\right)_{4}{ }^{2+}$. Thiourea in alkaline medium acts as an $\mathrm{S}^{2-}$ ion source. The chemical reaction that takes place towards CdS formation as follows

$$
\begin{aligned}
& \mathrm{Cd}\left(\mathrm{NH}_{3}\right)_{4}{ }^{2+}+\left(\mathrm{NH}_{2}\right)_{2} \mathrm{CS}+2 \mathrm{OH}^{-} \longrightarrow \mathrm{CdS} \downarrow+ \\
& \mathrm{CH}_{2} \mathrm{~N}_{2}+4 \mathrm{NH}_{3}+2 \mathrm{H}_{2} \mathrm{O}
\end{aligned}
$$

\section{PEC Measurement}

The electrical conductivity type of CdS layers was examined using PEC cell arrangement. The PEC cell was made by two electrodes which partially emerged in $10 \% \mathrm{NaCl}$ solution. One electrode is CdS-deposited FTO which forms a solid/liquid Schottky junction at $\mathrm{CdS} / \mathrm{NaCl}$ solution and the other is a purely carbon rod, and these electrodes were externally connected to a digital voltmeter. The open circuit voltage was measured under dark and illuminated condition produced by the $\mathrm{CdS} / \mathrm{NaCl}$ Schottky junction. The polarity of the voltage indicates the determination of conductivity type of CdS layer. Table 1 shows the obtained results of both as-deposited and annealed CdS samples. Both as-deposited and annealed CdS layers are observed to be n-type in electronic conduction and conversion efficiency improves after annealing.

Table. 1. Summary of PEC measurements for as-deposited and annealed CdS layers.

\begin{tabular}{|c|c|c|c|c|}
\hline Samples & $\mathrm{V}_{\text {dark }}(\mathrm{mV})$ & $\mathrm{V}_{\text {light }}(\mathrm{mV})$ & $\square \mathrm{V}(\mathrm{mV})$ & Comments \\
\hline As-deposited 1 & -250 & -520 & -270 & n-type \\
\hline As-deposited 2 & -218 & -485 & -267 & n-type \\
\hline As-deposited 3 & -216 & -500 & -284 & n-type \\
\hline Annealed 1 & -261 & -578 & -317 & n-type \\
\hline Annealed 2 & -233 & -534 & -301 & n-type \\
\hline Annealed 3 & -242 & -570 & -328 & n-type \\
\hline
\end{tabular}

\section{Optical properties}

The variation of optical absorption spectra as a function of wavelength was recorded for both as-deposited and annealed CdS layers in the wavelength range 400-1100 nm. Figure 1a shows optical absorbance with wavelength for as-deposited and annealed CdS film. It is observed that the absorbance is lower for as-deposited film than that of annealed film over the wavelength region $\sim 500 \mathrm{~nm}$ to $1100 \mathrm{~nm}$. Using absorption data, the band gap energy, $E_{g}$, of the CdS film was estimated by plotting $A^{2}$ against the photon energy (hv) and is shown in Fig. 1b. The linear nature of the plot indicates that $\mathrm{CdS}$ is a direct band gap material. The extrapolation of straight line to $h v=0$ axis gives the value of the band gap. The band gap energy, $E_{g}$, of asdeposited thin film was found to be $2.42 \mathrm{eV}$, which is equal to the bulk (standard) value for hexagonal $\mathrm{CdS}$ at room temperature $[2,4,22]$.

After annealing the sample at $673 \mathrm{~K}$ for 1 hour in air caused a decrease in band gap to be $2.27 \mathrm{eV}$. This band gap shift is also clearly understood from the change of the color of the asdeposited to annealed film and it is observed that the yellow color appearance for as-deposited layers and orange color 
appearance for annealed one. Decrease in the band gap could be attributed to the phase transition from cubic to hexagonal phase $[23,24]$ or more likely a reduction in strain within the film. Another possibility perhaps due to annealing process, increase in the grain size of the $\mathrm{CdS}$ film occurs. The effect of grain size on the optical band gap arises out of quantum confinement effects [25].

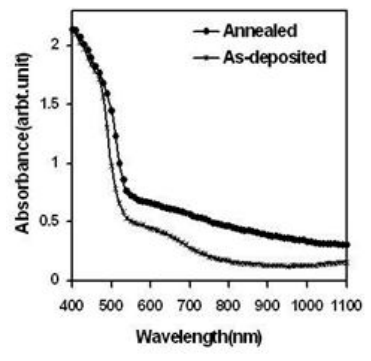

(a)

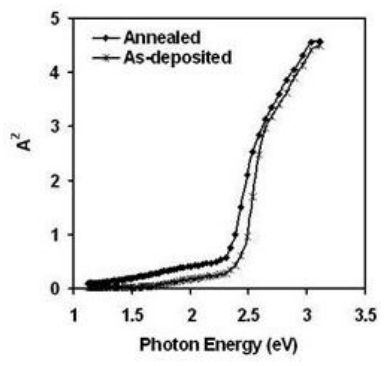

(b)
Fig. 1. (a) Absorbance (A) vs. wavelength, (b) $\mathrm{A}^{2}$ vs. photon energy.

\section{Surface morphology}

SEM is a convenient technique to study the surface morphology of thin film. SEM image for as-deposited and annealed CdS thin film is shown in Fig. 2. It is observed from SEM image that the as-deposited CdS film (Fig. 2a) is uniform and without any void, pinhole or cracks and covered the substrate well. The surface topology shows the clusters composed of nanoparticles of different sizes. Therefore, the average cluster size of as-deposited film were estimated from different clusters within the film and found to be about $150-300 \mathrm{~nm}$. SEM image of annealed film (Fig. 2b) showed a slight improvement in crystallinity. The annealing of these clusters has shown an enhancement of their mean size achieving diameters of 200-350 nm. This may be due to coalesce of smaller nanoclusters into larger clusters. The change in microstructure or surface morphology have been attributed to the partial transformation of zinc-blend cubic CdS phase into hexagonal wurtzite phase and/or partial conversion of $\mathrm{Cd}(\mathrm{OH})_{2}$ into $\mathrm{CdO}$
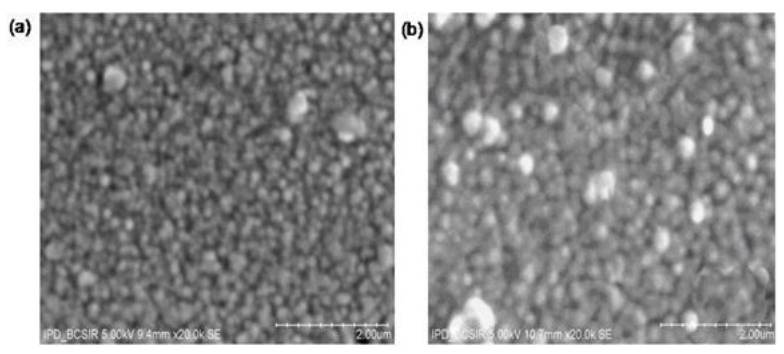

Fig. 2. SEM image of CdS thin film: (a) as-deposited and (b) annealed at $673 \mathrm{~K}$.

\section{Structural characterization}

CdS usually adopt two crystalline structures: hexagonal (wurtzite) or cubic (zinc-blend) structure. In order to study the crystal structures, the different phases present, grain size of the material and whether cubic or hexagonal transformation has taken place during annealing; XRD studies have been carried out on both as-deposited and annealed CdS films and is shown in Fig. 3. In case of as-deposited film (Fig. 3a), the main reflection can be assigned at $2 \theta=26.6^{\circ}$ have preferential orientation in either the [111] direction in the case of cubic modification [26] or the [002] direction in the case of hexagonal modification [27] which causes ambiguity. Due to the fact that most intense peaks of cubic and hexagonal phase coincide in the diffraction angle within $1 \%$, the interpretation of XRD spectra became difficult task.

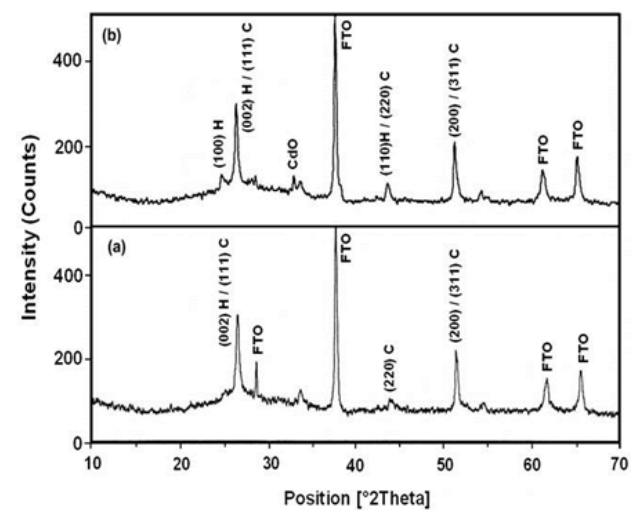

Fig. 3. XRD pattern of CdS thin film: (a) as-deposited and (b) annealed at $673 \mathrm{~K}$.

Upon annealing at $673 \mathrm{~K}$ in air for 1 hour, the diffraction peak (Fig. 3b) became more intense and sharper, and an evolution of other peaks appeared that belongs to the hexagonal phase. Thus annealing of $\mathrm{CdS}$ films confirms that the phase transition occurred from cubic to hexagonal phase. This is likely because of the reduction of strain in the film due to some degree of reorientation of the particles at higher temperature. It is also noticeable from Fig. $3 b$ that the width of the main peak of the annealed film is smaller than that of the as-deposited film; which implies reduced in strain within the film or increase in grain size during thermal annealing. The summary of XRD data and calculated structural parameters of $\mathrm{CdS}$ film are presented in Table 2.After annealing, the presence of $\mathrm{CdO}$ has also been identified at $2 \theta=33.07^{\circ}$ as can be seen in Fig. $3 b$ [28]. The origin of this phase could be due to oxidation processes or from reaction of any preformed cadmium hydroxide $\mathrm{Cd}(\mathrm{OH})_{2}$ [29]. The lattice constant (c) for both asdeposited and annealed film was determined from the $2 \theta$ value of (002) diffraction peak and the results are presented in Table 2. From the concept of surface energy, increase or decrease in the lattice constant is due to the

internal stress on the crystallite [30]. The as-deposited sample shows nearly same value of lattice constant that of bulk $\mathrm{CdS}$ $(6.719$ '). But upon annealing lattice constant slightly 
increase confirms that the stress is compressive in nature. This compressive stress is likely due to the native defects arising from the lattice misfit. The change in stress may be due to the re-crystallization process in the polycrystalline film. The crystallite size (D) was calculated using the Scherrer's formula, $\mathrm{D}=0.94 \lambda / \beta \operatorname{Cos} \theta$, where $\lambda(1.54056$ ' $)$ is the X-ray wavelength, $\theta$ is the Bragg's angle and $\beta$ is the full width at half maximum (FWHM) of the diffraction peak in radians. The calculated value of $\mathrm{D}$ is presented in Table 2. The average crystallite size was calculated by resolving (002) peak for hexagonal phase. It can be seen from the values of $\mathrm{D}$ that the as-grown CdS layer presents a nanocrystalline structure and an improvement of the grain size is observed after the heat treatment.

Table. 2. Structural parameters of both as-deposited and annealed CdS film.

\begin{tabular}{|c|c|c|c|c|c|c|c|c|}
\hline Sample & $\begin{array}{c}2 \theta \\
(\mathrm{deg})\end{array}$ & $\stackrel{d}{\prime}$ & $\begin{array}{c}\text { FWHM } \\
\text { (deg) }\end{array}$ & $\begin{array}{l}\text { Plane } \\
\text { [hkl] }\end{array}$ & $\begin{array}{c}\mathrm{D} \\
(\mathrm{nm})\end{array}$ & $10^{-4} \operatorname{m}^{-4} \operatorname{lin}^{-2}$ & $\begin{array}{c}\delta \\
10^{14} \\
\operatorname{lin} / \mathrm{m}^{2}\end{array}$ & $\begin{array}{c}\text { Lattice } \\
\text { constant c } \\
\left(\begin{array}{c}\prime \\
()\end{array}\right.\end{array}$ \\
\hline \multirow{3}{*}{$\begin{array}{c}\text { As- } \\
\text { deposited }\end{array}$} & 26.54 & 3.3585 & 0.2952 & $(002) \mathrm{H},(111) \mathrm{C}$ & \multirow{3}{*}{28.88} & \multirow{3}{*}{7.9} & \multirow{3}{*}{12} & \multirow{3}{*}{6.717} \\
\hline & 44.18 & 2.0501 & 0.9446 & $(220) \mathrm{C}$ & & & & \\
\hline & 51.49 & 1.77496 & 0.2558 & $(200) \mathrm{H},(311) \mathrm{C}$ & & & & \\
\hline \multirow{4}{*}{ Annealed } & 24.96 & 3.56687 & 0.4723 & $(100) \mathrm{H}$ & \multirow{4}{*}{48.1} & \multirow{4}{*}{5.8} & \multirow{4}{*}{4.3} & \multirow{4}{*}{6.735} \\
\hline & 26.48 & 3.36633 & 0.1771 & $(002) \mathrm{H},(111) \mathrm{C}$ & & & & \\
\hline & 43.79 & 2.06722 & 0.3936 & $(110) \mathrm{H},(220) \mathrm{C}$ & & & & \\
\hline & 51.51 & 1.77414 & 0.2165 & $(200) \mathrm{H},(311) \mathrm{C}$ & & & & \\
\hline
\end{tabular}

The micro-strain $(\varepsilon)$ and dislocation density $(\delta)$ have been calculated using the following relations [31] and their values are presented in Table 2: micro-strain $(\varepsilon)=w \cos \theta$ / 4 and dislocation density $(\delta)=1 / \mathrm{D}^{2}$, where $w$ is the FWHM and D is the crystallite size. It is observed that the micro-strain and dislocation density decreases after annealing expected to enhance the reduction in the concentration of lattice imperfections originating from lattice misfit in the film.

\section{Compositional analysis}

EDX analysis was performed for the elemental compositional analysis of the film. Figure 4 shows a EDX spectrum and its relevant analysis. The strong peaks for $\mathrm{Cd}$ and $\mathrm{S}$ were found in the spectrum. The observed EDX analysis is presented in Table 3. The average atomic percentage of $\mathrm{Cd}: \mathrm{S}$ was $55.77: 40.52$ showing that $\mathrm{Cd}$ is slightly more than the stoichiometric ratio. Such excess of $\mathrm{Cd}$ seems to be typical for chemically-deposited $\mathrm{CdS}$ thin film [5]. It can be due to coexistence of CdS with other $\mathrm{Cd}$ compounds, which are also intermediates or products of the CBD reaction [6]. $\mathrm{O}$ is also slightly identified. This is because of the aqueous alkaline nature of the bath; $\mathrm{Cd}(\mathrm{OH})_{2}$ is unavoidable and therefore $\mathrm{O}$ is being incorporated in the CdS film.

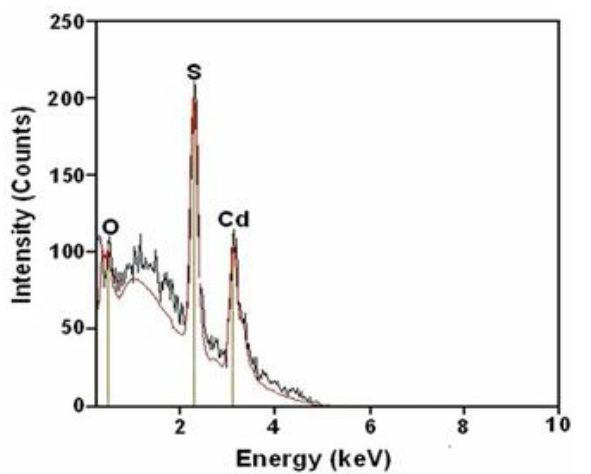

Fig. 4. EDX pattern of as-deposited CdS thin film.

Table. 3. EDX analysis of as-deposited CdS film.

\begin{tabular}{|c|c|c|}
\hline Element & Atom\% & Atom\% Error \\
\hline $\mathrm{Cd}$ & 55.77 & $+/-4.82$ \\
\hline $\mathrm{S}$ & 40.52 & $+/-2.14$ \\
\hline $\mathrm{O}$ & 3.71 & $+/-1.26$ \\
\hline
\end{tabular}

\section{Electrical Properties}

The electrical conductivity of the CdS films were measured by two-point probe method in the temperature range 302-402 K. The change in electrical conductivity $(\sigma)$ of CdS thin film with temperature $(\mathrm{T})$ is shown in Fig. 5. The variation of $\sigma$ vs $T$ suggests the semiconducting nature of the thin film but conductivity increases non-linearly with the increase in temperature. This may be explained as a result of structural 
changes occurring in this film with temperature. Asdeposited film contains some lattice defects as well as geometrical and physical imperfections which randomly distributed on the surface and the volume of the film. Geometrical imperfection includes surface roughness and grain boundaries in the volume. The structure is an important factor which is responsible for the physical properties of thin film. As temperature increases the structure of the film causes a considerable increase in average grain size which has been seen in SEM and XRD measurements, and therefore a decrease in grain boundary area. This is because of coalescence of smaller crystallite into larger one. These structural changes cause a decrement in the electrons scattering, and consequently the carrier concentration also increases with the increase of temperature. And therefore finally conductivity of the film increases.

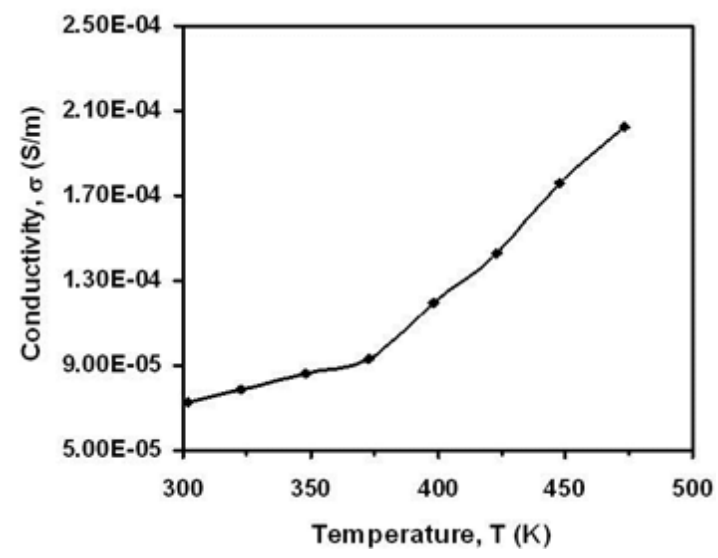

Fig. 5. Variation of $\sigma$ vs $\mathrm{T}$ of CdS thin film.

The activation energy of electrical conductivity was found using well known exponential law:

$$
\sigma=\sigma_{\mathrm{o}} \exp \left(\mathrm{E}_{\mathrm{a}} / \mathrm{kT}\right)
$$

where $\sigma_{\mathrm{o}}$ is the pre-exponential factor, $\mathrm{E}_{\mathrm{a}}$ is the activation energy of the electrical conduction, $\mathrm{k}$ is the Boltzmann constant and $\mathrm{T}$ is the absolute temperature. The value of $\mathrm{E}_{\mathrm{a}}$ can be determined by plotting $\ln (\sigma)$ vs $1000 / \mathrm{T}$ and is shown in Fig. 6. The curve clearly shows two conduction regions. The first, in the low temperature range $(T=302$ 375), is characterized by small slope. In the higher temperature range, the curve is characterized by large slope. From the slopes, activation energy is calculated and is obtained $0.03 \mathrm{eV}$ for lower temperature region and 0.12 $\mathrm{eV}$ for higher temperature region, respectively. It suggests that as a result of thermal energy, transition of excited charge carriers occurs from donor level to the conduction band.

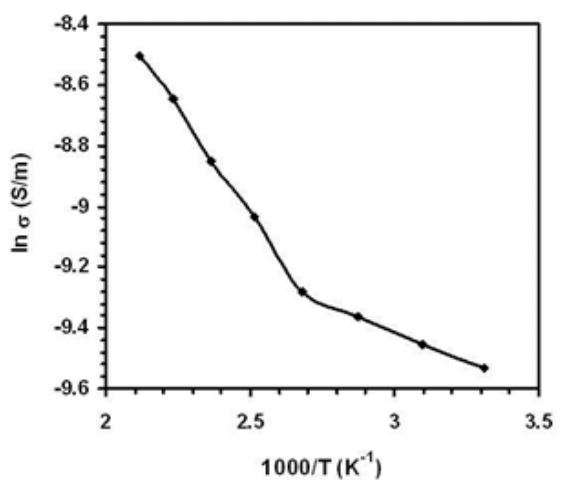

Fig. 6. Variation of $\ln \sigma$ vs $\mathrm{T} / 1000$ of CdS thin film.

\section{Conclusions}

A thin film of CdS prepared by CBD technique on TCO glass substrate showed good adherence to the substrate. XRD studies showed that the films include both cubic and hexagonal structures as mixture. The number of hexagonal phase in the film was seen to increase by annealing. Strain and dislocation density present in the film are found to decrease due to thermal annealing and decrease of lattice constant also implies that the stress is compressive in nature which is likely to be governed by the dominant recrystallization process. The crystallite size was found to be 28.88

$\mathrm{nm}$ by resolving (002) peak for hexagonal phase and $48.1 \mathrm{~nm}$ after annealing. SEM studies confirm that the formation of large clusters about 150- $300 \mathrm{~nm}$ become larger about 200-350 $\mathrm{nm}$ upon thermal annealing. The observed annealing effects on optical band gap shows a reduction from $2.42 \mathrm{eV}$ to $2.27 \mathrm{eV}$ with a clear color change from yellow to orange. The increase in the electrical conductivity with the increase of temperature is due to the increase of grain size and carrier density.

\section{Acknowledgements}

This work is partly supported by the Bose Centre for Advanced Study and Research in Natural Sciences, University of Dhaka. The authors acknowledge the support of Semiconductor Technology Research Centre (STRC), University of Dhaka for providing laboratory facilities.

1. Mathew, X., G.W. Thompson, V.P.Singh , J.C. McClure,S. Velumani.,N.R. Mathwes ,P.J. Sebastian, Sol. Energy Mater. Sol. Cells, 76, 293 (2003).

2. Enrique, J .P., X. Mathew, Sol. Energy Mater. Sol. Cells, 76, 313 (2003).

3. Herrero,J., M. T. Gutierrez, C. Guillén, J. M. Dona, M. A. Martinez, A. M. Chaparro, R. Bayon, Thin Solid Films, 361362, 28 (2000).

4. Guillén,C., M. A. Martíne, C. Maffiotte, J. Herrero, J Electrochem. Soc., 148, G602 (2001).

5. Angel, O.Z., M.L. Morales, Phys.Rev., B, 62, 13064(2000)

6. Matra, S., A.mandal, S. Banerjee, A. Datta, S. Bhattacharya, A.Bose, D. Chakravorty,Indian J. Phys., 85, 649(2011) 
7. Karimi,M., M. Rabiee, F. Moztarzadeh, M. Tahriri, M. Bodaghi, Current Appl. Phys. 9, 1263 (2009).

8. Kariper,A., E. Güneri, F .Göde, C .Gümüs, T. Özpozan, Mater. Chem. and Phys. 129, 183 (2011).

9. Krishnakumar,V., J. Han, A. Klein, W. Jaegermann, Thin Solid Films, 519, 7138 (2011).

10. Samantilleke, A.P., M. F. Cerqueira, S. Heavens, P. Warren, I. M. Dharmadasa, G. E. A. Muftah, C. J .R Silva, B. Mari, Thin Solid Films, 519, 7583 (2011).

11. Chun,S., Y. Jung, J. Kim, D. Kim, J. Crys. Growth, 326, 152 (2011).

12. S Tec-Yam,S., R. Patiño, A. I. Oliva, Current Appl. Phys., 11, 914 (2011)

13. Barote,M.A., A. A. Yadav, E. U. Masumdar, Physica B Conden. Mat., 406, 1865 (2011).

14. Wan,L., Z. Bai, Z. Hou, D. Wang, H. Sun, L. Xiong, Thin Solid Films, 518, 6858 (2010).

15. Oliva-Avile's,A.I., R. Patiño, A. I. Oliva, Appl. Surf. Sci., 256, 6090 (2010).

16. Sasikala,G., R. Dhanasekaran, C. Subramanian, Thin Solid Films, 302, 71 (1997).

17. Dushkina,N.M., B. Ullrich, H. Sakai, Y. Segawa, K. Hibino, T. Eiju, Thin Solid Films, 360, 222 (2000).

18. Pouzet,J., J.C Bernede, A. Khellil, H. Essaidi, S. Benhida, Thin Solid Films, 208, 252 (1992).
19. Mahmoud S A, A A Ibrahim, A S Riad, Thin Solid Films, 372, 144 (2000).

20. Acevedo A M, O V Galán, G C Puente, J V Larramendi, G A Mejía, M C Castañeda, A E Esquivel, H H Contreras, A A Carbajal, F C Gandarilla, Proceedings of the 29th IEEE Photovoltaic Specialists Conference 2002, 624.

21. Chowdhury,R.I., M A Hossen, G Mustafa, S Hussain, S N Rahman, S F U Farhad, K Murata, T Tambo, A B M O Islam, Int. J. Mod. Phys. B, 24, 5901 (2010).

22. Bhargava (Ed.).,R.N., Properties of Wide Bandgap II-IV Semiconductors, EMIS Datareviews Series No. 17 (INSPEC, London, UK, 1997).

23. Ichimura,M., F. Goto, E Arai, J. Appl. Phys, 85, 7411 (1999).

24. Metin H, S Erat, S Durmus, M Ari, Appl. Surf. Sci., 256, 5076 (2010).

25. Yu,I., T. Isobe, M .Seena, Mater. Res. Bull, 30, 75 (1995).

26. JCPDS card no: 10-0454.

27. JCPDS card no: 41-1049.

28. JCPDS card no: 05-06400.

29. Metin, H., and R. Esen. J. Cryst. Growth, 258, 141 (2003).

30. Chopra,K. L., Thin film Phenomena, (McGraw-Hill, New York, 1969) p. 191.

31. Senthilarasu,S., R. Sathyamoorthy, S. Lalitha, Sol. Energy Mater. Sol. Cells, 82, 299 (2004). 
Dhaka Univ. J. Sci. 60(2): 283-288, 2012 (July)

\#Corresponding Author (O. Islam): Fax: +880-2-8615583; E-mail: oislambd@ yahoo.com 